\title{
Investigating the Mediating Role of Learning Strategies (Cognitive and Metacognitive) between Emotional Intelligence and Academic Performance among Students of Smart and Ordinary School
}

\author{
Ismail Sadipoura, Soghra Ebrahimi Ghavama ${ }^{a}$, Noorali Farrokhi ${ }^{\mathrm{b}}$, Hassan \\ Assadzadeh ${ }^{a}$, Nahid Sametia
}

aDepartment of Educational Psychology, University Allameh Tabatabaei, Tehran, IRAN 'Department of Assessment and Measurement, University Allameh Tabatabaei, Tehran, IRAN

Education system is efficient and successful when the academic achievement of students in different periods shows highest and lowest numbers. Smart schools are an environment that has the potential necessary to accomplish this goal. However, academic performance is affected by many variables. The aim of this study was investigating the mediating role of learning strategies (cognitive and metacognitive) between emotional intelligence and academic performance amons students of smart and ordinary school. The study in term of method is predictive- correlational. The population in this study consisted of all high school students in Tehran using multi-stage cluster sampling 583 students were selected as sample. The results showed that the direct and indirect effect of emotional intelligence and achievement motivation on students 'academic performance is significant. The direct and indirect effect of emotional intelligence and achievement motivation on students' academic performance in smart schools is significantly higher than its impact on the academic performance of students in ordinary schools. The role of smart schools in important variables such as emotional intelligence, achievement motivation and academic performance makes the role of smart schools brighter and stronger. Using and applying smart and updated technology, on the one hand, improve the teaching-learning in teachers and students, the teachers and students to use the World Wide Web can upgrade their academic level and the development of the country. The results indicate the usefulness to policymakers in the field of education.

KEYWORDS

smart schools, emotional intelligence, learning strategies, academic performance
ARTICLE HISTORY

Received 15 September 2016 Revised 10 November 2016 Accepted 22 February 2017

\section{Introduction}

Identify factors predicting academic performance is important and followed expand socio-political implications (Perera, 2016). In 2011, the member

\section{CORRESPONDENCE Nahid Sameti}

(c) 2017 Sadipour et al.

Open Access terms of the Creative Commons Attribution 4.0 International License apply. The license permits unrestricted use, distribution, and reproduction in any medium, on the condition that users give exact credit to the original author(s) and the source, provide a link to the Creative Commons license, and indicate if they made any changes. (http://creativecommons.org/licenses/by/4.0/) 
countries of the Organization for Economic Cooperation and Development (OECD) average of more than 6\% of gross domestic product (GDP) spent on education (Organization for Economic Co-operation and Development, 2014). In addition, between 2000 and 2011, the rate of growth spending in education across almost all member states, greater than the rate of GDP growth (Organization for Economic Co-operation and Development, 2014). Hence, the academic achievement of students as an important indicator for the evaluation of educational systems is considered. In addition, academic achievement ever for teachers, students, parents, theorists, and educational researchers also is important. For example, learners' achievement is one of the main criteria for evaluating the performance of teachers. Academic average also represents the scientific abilities of students to enter the world of work and employment and higher educational levels. This is probably due to the importance of many educating theorists in their studies having focused on factors affecting academic achievement (Fardanesh, 2004).

Smart school as one of the most important components of this system is a dynamic and learner education organization that the learning process and improve management systematically has been restored to different levels of students to prepare for life in the age of information and communication.

A smart school as a learning organization, has evolved over time, and continues its professional staff, educational resources and their ability to enforcement expand. This allows school students as continually to live in the information age is preparing itself to adapt to changing conditions. To operate effectively, smart school need specialist staff and have proper planning processes with the strong support (a smart way of schools, 2011).

According to Brokowshi (1990) new psychological research, particularly in relation to the three main findings have revealed student learning. The first finding is that students must be strategic and to communicate between new knowledge and prior knowledge pay to strategies. The second finding is that students must master metacognitive knowledge and used it to control the thinking and the third finding is that students believe they are responsible for their own learning (quoting Seifeet, Wheeler, 1992).

About another aspect of emotional intelligence problems can be said the defined emotional and social intelligence learning as much to learn math and reading are important. Learn unrelated will not be realized with children's feelings.

In studies of this kind, it has repeatedly shown that when children has not the skills to cope with their problems or listening skills or focus, sense of responsibility about their assignments, or lack importance of education, and so the value of their investments (Goleman, 1995). Love and Nelson (2006) claimed that emotional intelligence is a crucial factor for personal health and academic success of students.

They claimed that students with emotional intelligence skills are better able to deal with difficult and complex experience of college. finally it should be noted that today the country's school education system needs by using information and communication technology (ICT), the possibility of continuous learning and provide new opportunities for people to experience life in the information society, so that this technology not as an instrument, but also in terms of enabling infrastructure for education and professional training considered.

Smart schools are an environment that has the potential necessary to accomplish this goal. The role of smart schools in important variables such as 
emotional intelligence and academic performance makes the role of smart schools brighter and stronger.

\section{Theoretical foundation and research background}

There are different definitions of emotional intelligence provided by experts:

Emotional intelligence can be used in a wider sense as the ability to use emotional information in a constructive and consistent manner. Emotional information consisted of individual mental and emotional reactions communicated the emotional reactions of others (Bar-On, Parker, 2011, p. 173). Daniel Goleman defined emotional intelligence as the ability to motivate and perseverance in failure and delaying gratification needs to set the mood and prevent mental disorders, pain and suffering, hope and solidarity (Goleman, 1995, p. 317, quoting Stosa, Rocco, 2013).

Academic performance is a set of academic behavior that progress in two dimensions of achievement or declining academic achievement in the field of achieving information. This function can be used in conjunction with other factors such as school and university classroom activities and communicate with classmates and professors (Maw, 1997 According to Shaver, Salimi and Homaee, 2008).

Smart School is learning the result of thinking and a good thinking by all students can learn and as schools where students are grown, smart schools, where it is necessary for staff development, management and teachers as well.

The smart school is a place where the interests of intellectual and professional collaboration, encouraged and supported (How smart a school, 2011)

According to Flavell (1998), the thing person with knowledge of the process of cognitive related products is metacognitive. In this sense, the emphasis is on the process of thinking.

He says metacognitive knowledge may be distinguished from cognitive knowledge but the distinction between the two in how they use the information. Hence, the only difference between them, choose carefully and not blindly assessed and guidelines. There are many definitions of metacognition: knowledge of the processes and cognitive strategies (Masters, 1981; quoted Flavell, 1985); thinking about thinking (Brown, 1984; quoted by Glover and Bruning, 1990); Knowledge and control about thinking and learning activities applied (Cross and Paris, 1988); knowledge of knowing (Miller, 2002; quoted Atarkhameh, 2009) and his knowledge of how their own learning (Slavin, 2006; according to Saif al, 2008).

\section{Research background}

Jafari and Vahedzadeh (2014) in a cross - sectional correlational examined the relationship between the components of emotional intelligence and academic achievement of students.

The study population included 126 female and 95 male students of Shahid Beheshti University of Medical Sciences who were selected by simple random sampling. The research instrument was Bar-On questionnaire. This study results showed that there is a significant positive correlation between emotional intelligence and academic achievement. Also, generally between gender and emotional intelligence a significant relationship was not found but regression 
multivariate stepwise showed that the three components of emotional intelligence, decisiveness, optimism and emotional awareness are significant predictive role of academic achievement.

Mousavi, Jabalameli and Ali Bakhsh (2014) in a study examined the relationship between emotional intelligence and self-regulated learning strategies and motivational beliefs on students' academic performance. To this end, 1300 students from all undergraduate students of Isfahan University of Medical Sciences using randomly stratified sampling as sample size were selected. Measurement instruments were two Bar-on Emotional Quotient Inventory and Motivational Strategies for Learning (MSLQ). Path coefficients are related to the interpersonal relationships and empathy factor was not significant. The path coefficient of the components of happiness, realism and responsibility with motivational beliefs were not significant. The effect of selfregulated learning strategies and motivational beliefs on academic performance, all paths was significant and the effects of emotional intelligence and selfregulated learning strategies and motivational beliefs on academic performance of all paths showed a significant relationship.

Hatami, Taghizadeh and Mohebinia (2012) investigated the relationship between emotional intelligence, self-regulated learning and academic selfconcept and academic performance in high school third grade male students in Kashan city.

The sample size 340 students were selected using simple random sampling. Data collection tools include Schering emotional intelligence questionnaire, Pintrich self-regulated learning strategies and Beck \& Steer academic selfconcept questionnaire. The results showed that there is a significant positive correlation between the components of emotional intelligence, self-regulated learning and academic self-concept and academic performance. The results of stepwise regression analysis showed that the components of cognitive strategies, self-regulation, academic self-concept, self-control and self-motivation has a significant role in explaining and prediction of academic performance and in five steps and totally unable to explain 0.391 of the variance in academic performance.

Sureshjani Bakhshi (2008) in a study examined the relationship between emotional intelligence and mental health and academic performance evaluated. For this purpose 200 students of Behbahan Islamic Azad University using stratified random sampling in equal proportions of both genders were selected and emotional intelligence questionnaire, as well as Goldberg's General Health Questionnaire (GHQ) was completed. The findings showed that there is a positive correlation between emotional intelligence and all of its components and variables of academic performance and mental health of students.

There was a significant difference between variables of emotional intelligence and its components (except for components of happiness, self-actualization and interpersonal) and academic performance in males and females and overall mean of emotional intelligence are more female students than male students. Results showed that emotional intelligence, mental health and academic performance significantly and positively predicted.

Mirzajani and Dellaviz Biklaee (2013) in a study called emotional intelligence of students in smart schools, within an experimental method using pre-test / posttest with control group showed that the smart school students than students in ordinary schools is significantly higher than emotional intelligence. 


\section{Research Methodology}

With respect to the question, hypothesis and purpose of the research methodology of this study, was predictive- correlational. The study aimed to examine change one or more variable, with some changes to one or more other variables. The present study aimed to examine variables such as emotional intelligence, problem-solving skills and academic achievement in predicting academic performance of students of ordinary and smart school. The population in this study is all high school students in Tehran. According to the Education Department of Tehran Province, the total high school students (sixth, seventh and eighth grades) and the second high school (ninth, tenth and eleventh grades) are equal to 756329 people, of which 507489 on ordinary schools and 248840 students are enrolled in smart schools.

The multi-stage cluster sampling method used, selected sample accurately represents the population studied. Cochran formula was used to estimate the sample size.

To collect the data, Bar-On Emotional Intelligence Scale (2000), Dortaj academic performance questionnaire (2014) and Learning Strategies Questionnaire (Karami, 2002) is used. In this study, the descriptive data, mean, frequency, tables and graphs and to evaluate hypotheses and causal relationships between variables was used path analysis. Data analysis was performed using AMOS software.

\section{Results}

\section{research hypotheses}

First hypothesis: emotional intelligence directly affects academic achievement. To test this hypothesis and the second hypothesis, Structural equation modeling was used as drawn in diagram 1. Diagram 1 standardized coefficients and factor loadings of each dimension are reported. Before any interpretation of the results, fitness indicators of model should be considered. In Table 1 this path coefficients has been reported.

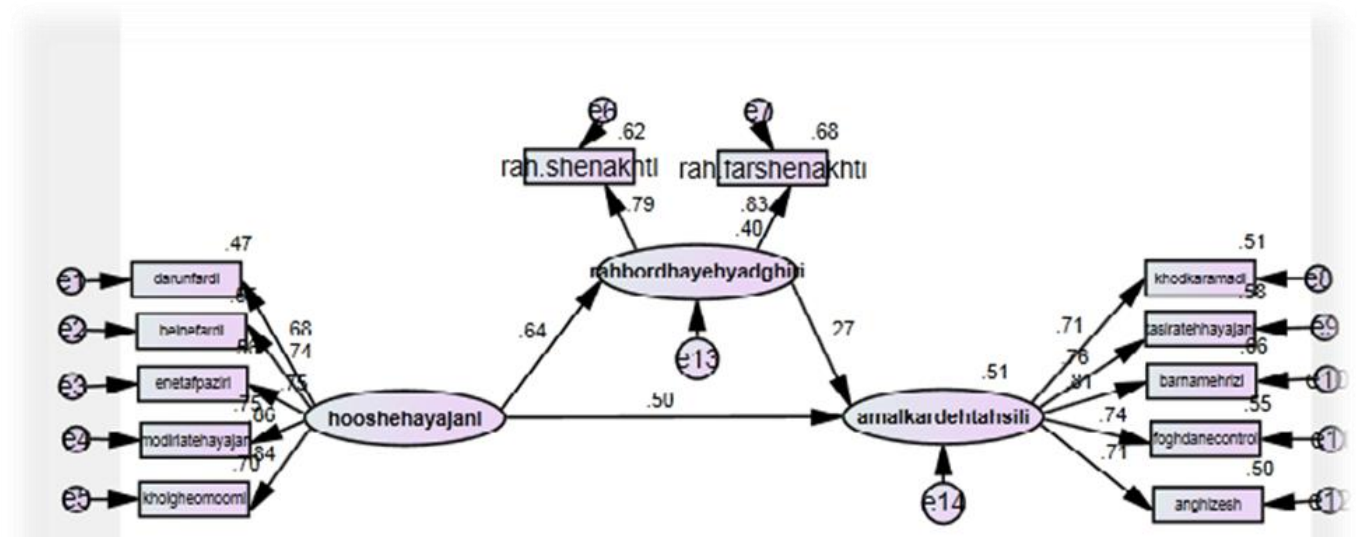




\section{Diagram 1. Structural equation modeling to investigate the learning strategies in mediating role between emotional intelligence and academic performance}

According to Table 1 it is clear that all three fitness index value is acceptable. This result implies that one can interpret the data obtained from the model, because that model 2 is fitted to the data.

Table 1. Fitness index of the data with model 2

\begin{tabular}{|l|l|l|}
\hline Fitness index & obtained value & acceptable amount \\
\hline Chi square & $\begin{array}{l}577.730 \text { (degrees of freedom } \\
\text { equal to 41) }\end{array}$ & Non-significant \\
\hline NFI & 0.93 & Higher 0.90 \\
\hline CFI & 0.91 & Higher 0.90 \\
\hline GFI & 0.92 & Higher 0.90 \\
\hline RMSEA & 0.07 & Smaller 0.08 \\
\hline
\end{tabular}

In fact, the results show that learning strategies can act as an intermediate or mediating variable. For a detailed review of the results, standard regression, and non-standard coefficients predicted in Table 2 have been reported. According to this table it is clear that all path coefficients are statistically significant $(\mathrm{P}<.01)$. According to the results reported in Table 2 it is clear that the standard coefficients of predicting academic performance through emotional intelligence is equal to 0.335 and the value of the correlation coefficient at the level of $\mathrm{P}<.01$ was significant. The standard coefficients of predicting academic performance through learning strategies is equal to 0.362 .

Table 2. Standard and non-standard regression coefficients predicting academic performance and emotional intelligence and learning

\begin{tabular}{|l|l|l|l|l|l|l|l|}
\hline $\begin{array}{l}\text { Dependen } \\
\mathrm{t}\end{array}$ & predictor & $\begin{array}{l}\text { Non- } \\
\text { standardized } \\
\text { coefficients }\end{array}$ & $\begin{array}{l}\text { Standardized } \\
\text { coefficients }\end{array}$ & $\begin{array}{l}\text { Standa } \\
\text { rd } \\
\text { deviati } \\
\text { on }\end{array}$ & $\begin{array}{l}\text { Critical } \\
\text { value }\end{array}$ & $\begin{array}{l}\text { signific } \\
\text { ance } \\
\text { level }\end{array}$ \\
\hline $\begin{array}{l}\text { Learning } \\
\text { strategies }\end{array}$ & $\rightarrow$ & $\begin{array}{l}\text { Emotional } \\
\text { Intelligence }\end{array}$ & .636 & .320 & .026 & 12.491 & 0.01 \\
\hline $\begin{array}{l}\text { Academic } \\
\text { Performanc } \\
\mathrm{e}\end{array}$ & $\rightarrow$ & $\begin{array}{l}\text { Learning } \\
\text { strategies }\end{array}$ & .275 & .362 & .076 & 4.779 & 0.01 \\
\hline $\begin{array}{l}\text { Academic } \\
\text { Performanc } \\
\mathrm{e}\end{array}$ & $\rightarrow$ & $\begin{array}{l}\text { Emotional } \\
\text { Intelligence }\end{array}$ & .505 & .335 & .039 & 8.688 & 0.01 \\
\hline
\end{tabular}

But the most important part of this hypothesis is whether emotional intelligence directly affects academic performance or not?

To answer this question, standardized direct effects in Table 3 have been reported. According to this table it can be concluded that the size of the direct impact of emotional intelligence on academic performance is equal to 0.505. The value of the regression coefficient has a significant amount of data is considered to be statistically powerful.

Table 3. Standardized direct effects for model 2 


\begin{tabular}{|l|lll|}
\hline & $\begin{array}{l}\text { Emotional } \\
\text { Intelligence }\end{array}$ & $\begin{array}{l}\text { Learning } \\
\text { strategies }\end{array}$ & $\begin{array}{l}\text { Academic } \\
\text { Performance }\end{array}$ \\
\hline $\begin{array}{l}\text { Learning } \\
\text { strategies }\end{array}$ & .636 & .000 & .000 \\
$\begin{array}{l}\text { Academic } \\
\text { Performance }\end{array}$ & .505 & .275 & .000 \\
\hline
\end{tabular}

Second hypothesis: the emotional intelligence indirectly affected academic achievement by mediating role of learning strategies.

Sobel test was used to test this hypothesis. In fact, Sobel test is used to evaluate the mediating role of a variable.

Table 4. Sobel test for testing the mediating role of learning strategies on academic performance and emotional intelligence

\begin{tabular}{|l|l|}
\hline Sobel test & 4.4421039 \\
\hline a domain probably & 0.00000445 \\
\hline two domains probablyre & 0.00000891 \\
\hline
\end{tabular}

Third hypothesis: the direct effect of emotional intelligence and academic performance of students in ordinary and smart schools is different.

In hypothesis third to fourth type of school as a moderating variable is evaluated. The difference between the fitness values of chi-square method and CFA used to examine the role of schools in moderating the relationship between the variables. In fact, this method is a prerequisite for a group comparison that specifies that the measurement models are unchanged between groups.

That is, they have similar regression coefficients. According to Chen (2007) and more difference than $0.01 \mathrm{CFA}$ and more than 0.015 represent there is a significant difference between the two models and two models are not similar. Or in other words, moderating variable has significant role in moderating the relationships between variables measuring the structural model.

In summary, for the moderating role of school type (ordinary or smart) in structural models must first be calculated fitness indices of models then the difference between these indices based on Chen method examined. If there is a significant difference between fitness indices of two models, we can conclude that there was a significant difference in structural relationships of variables. The same consideration of direct path coefficient for both groups and run the AMOS software using MULTI-GROUP SEM revealed that the amount of the difference RMSEA and CFA is more than enough to be invariant in the two groups.

So it can be concluded that there is a difference between the two groups in the direct path coefficient. Analysis of the structural model for each group separately indicate the path coefficient between emotional intelligence with academic performance for students in smart schools is much more than ordinary schools (see diagrams 1 and 2). 


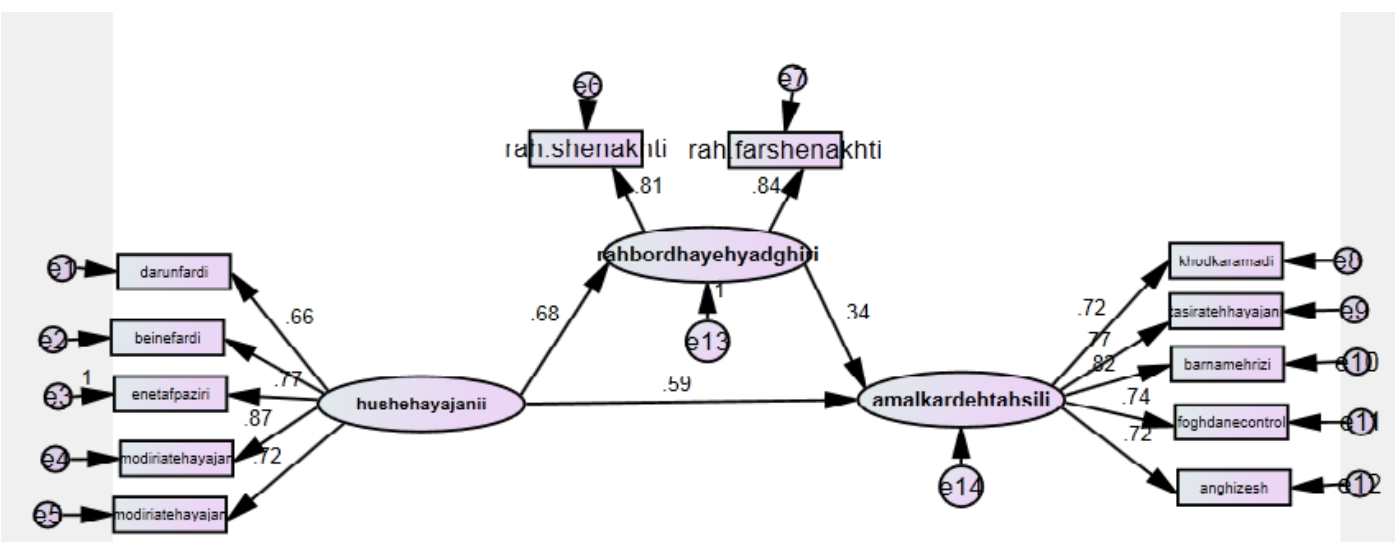

Diagram 2. Structural equations modeling to investigate the mediator role of learning strategies and emotional intelligence in academic performance (smart schools)

According to diagram 1 it is clear that the direct path coefficient between emotional intelligence and academic performance is equal to 0.59. Also according to the diagram (2) path coefficient for the group of ordinary students is equal to 0.44 .

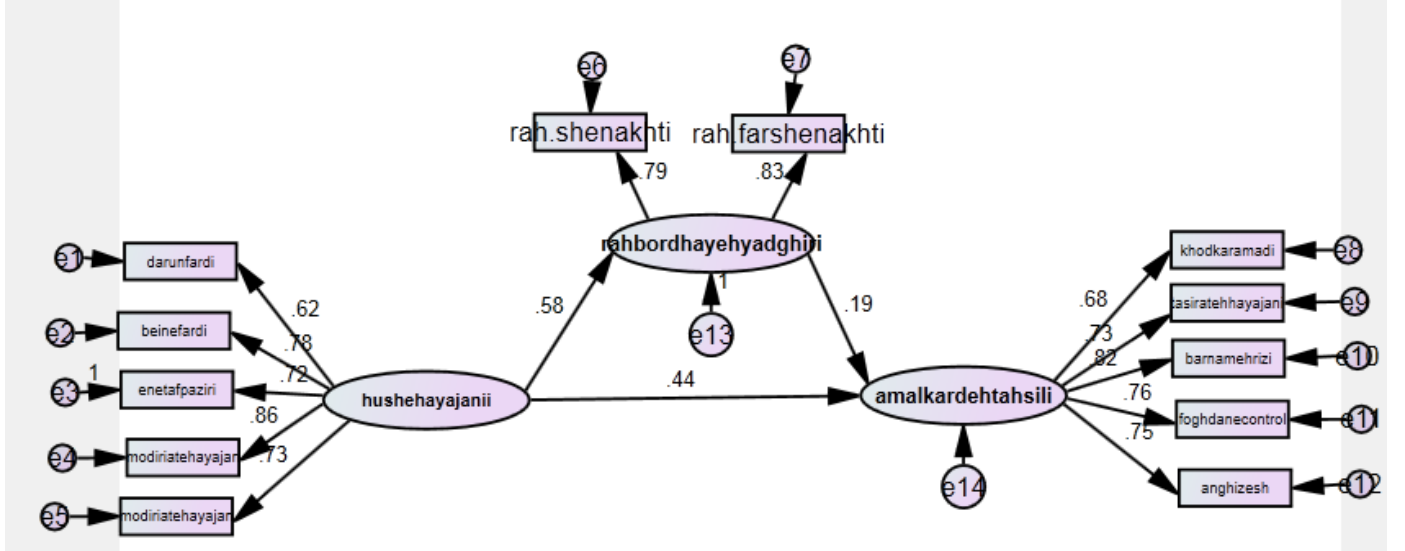

Diagram 3. Structural equations modeling to investigate the mediator role of learning strategies and emotional intelligence in academic performance (ordinary schools)

Thus, it was concluded that the direct path coefficient between emotional intelligence and academic performance for students in smart schools is more than ordinary schools.

Fourth hypothesis: indirect effect of emotional intelligence and academic performance among students in smart and ordinary schools different.

To investigate this hypothesis, first the indirect coefficients of emotional intelligence on the academic performance that show regression coefficient of emotional intelligence on learning strategies and regression coefficient of learning strategies on academic performance for an amount equal to the two in structural models was bounded. Then, by using Chen method difference between the values of RMSEA and CFA were calculated for both models. Given that difference between the two groups was invariably higher than the standard value, it became clear that there are differences between the two models in indirect factors. According to values reported in diagrams (1) and (2) specify 
that indirect standardized coefficients for the smart school students are higher than ordinary schools. Therefore, it was concluded that indirect coefficient of emotional intelligence on academic performance for students in smart schools is higher than ordinary schools.

\section{Discussion and Conclusion}

First hypothesis: emotional intelligence directly affects academic performance. As you can see, the data analysis showed that emotional intelligence directly affects academic performance. In other words, it was shown that the size of the direct impact of emotional intelligence on academic performance is equal to 0.505 that the value of the regression coefficient is a significant amount of data. The findings of study is inconsistent with findings Gross, 2005, and is consistent with findings Jager 2007; Jafari and Ahadzadeh 2014; Hatami Taghizadeh and Mohebbinia 2012, Bakhshi Sureshjani 2008; Nikoogoftar 2008 and Bakhshi Sureshjani 2008. It seems academic performance by being able to set personal goals and optimistic vision and motivation, and met them facilitated (Bar-On, 2005).

Bar-On suppose the assessment of the level of emotional intelligence among students significantly in anticipation of their study can be used. He argues that such information can be guided intervention with students who need to identify and to enhance the social and emotional intelligence competencies and skills will aid in optimal academic performance (Mahzon et al., 2013).

Accordingly, emotional intelligence can be much more important than cognitive intelligence, and many students due to lack of emotional - social skills, at risk of academic failure are required to learn the skills of emotional intelligence (Alkinsin and Alkinsin, 2003). Emotional intelligence training, negative emotions, violent behavior and substance abuse can reduce and the success and academic performance is affected.

The idea of training the students is in line with the Aristotelian ideology that emotions play a central role in their emotional experience. The feelings imbued with wisdom and penetrated with systematic training (Jeshi, Seri and Stoap, Rychardhary, 2012).

Second hypothesis: the emotional intelligence indirectly affected academic performance by mediating role of learning strategies.

In connection with this hypothesis Sobel test results (Table 4) showed the research hypothesis is confirmed, this means that learning strategies can play a mediating role in the relationship between emotional intelligence and academic performance.

This finding is consistent with studies Mousavi, Jabalameli and Ali Bakhsh (2014); Inglés et al. (2016); Fernández, Salamonson, \& Griffiths, (2012); Pekrun et al.(2002); Reimer ( 2003) and is inconsistent with Lischetzke and Eid (2003). Empirical studies show that emotional intelligence is very important to improve and develop learning strategies (Ingléset al., 2016; Fernández, Salamonson, \& Griffiths, 2012; Pekrun et al., 2002; Reimer, 2003). The use of learning strategies require behavioral, psychological, and emotional and excitement in the form appropriate to the learning environment shown (Dunn \& Griggs, 2000; Yip, 2013). Students who have higher emotional intelligence, are happier, has more collaboration and participants more effective to learn (Nelson, Nelson and Low, 2006). Emotional aspects effect on cognitive variables related to the 
learning and use learning strategies (Aynglz et al., 2016). Pekrun et al (2002) also suggest that positive emotions using creative and flexible learning strategies such as organizing, development, critical evaluation and monitoring of cognitive facilitated and this leads to increased learning and thus improve students' academic performance.

Third hypothesis: the direct effect of emotional intelligence and academic performance of students in ordinary and smart schools is different.

As abovementioned, the hypothesis third to fourth, type of school as a moderating variable examined. It was shown that (diagrams 1 and 2) there is a direct difference between two groups in term of path coefficient. Analysis of the structural model for each group separately showed that the direct path coefficient between emotional intelligence and academic performance for students of smart schools is much more ordinary schools.

According to these findings, it seems compared to ordinary schools, emotional intelligence in smart schools, has a greater share in the academic success of students that finding of this study is consistent with studies Charitaki, 2015, Marzukiet al., 2015; Mirzajani and Dellaviz Biklaee, 2013; Schultz-Zehnder et al., 2002 .

One of emotional intelligence strategies of students is that we find new approach to school performance. This means that it is a place to see the training of the students targeted. In other words, in the classroom, we should know thinking and feeling together (Parsa, 2001). Smart schools are an environment that has the potential necessary to accomplish this goal. For example, smart schools can be self-aware that is one of the main components of emotional intelligence to foster in students. If self-aware defined as the ability to self-reflection and selfawareness and the ability recognize themselves as distinct from the individual and the environment, learning through computers and digital devices, will have a big impact on students' self-awareness. On the other hand, the flexibility of digital media tools and a platform for creativity, which is undoubtedly one of the most important factors, are self-awareness (Furger, 2001). Sylwester (1998) is the electronic media force is more than anything else in their emotional content; communication media includes emotional elements that force students to pay attention. Media designers with the strong emotional elements in their programs draw the attention of users.

Fourth hypothesis: indirect effect of emotional intelligence and academic performance of students in smart and ordinary schools is different.

According to reported values in diagrams (1) and (2) it was found that standardized direct coefficients for the smart school students is higher than ordinary schools. Therefore, it was concluded that indirect coefficients of emotional intelligence on academic performance for students in smart schools is higher than ordinary schools. In other words, based on these findings, the impact of emotional intelligence of students in smart school on learning strategies as well as the impact of learning strategies on academic performance of these students is more than ordinary students that explain these findings can be pointed to several issues. As previously mentioned, studies show that emotional intelligence of students in smart schools is more than students in ordinary schools (Charitaki, 2015, Marzuki et al., 2015; Mirzajani and Dellaviz Biklaee, 2013; Schultz-Zehnder et al, 2002) Emotional aspects effect on cognitive variables related to the learning and use learning strategies (Aynglz et 
al., 2016). Pekrun et al (2002) also suggest that positive emotions using creative and flexible learning strategies such as organizing, development, critical evaluation and monitoring of cognitive facilitated and this leads to increased learning and thus improve students' academic performance.

\section{Conclusion:}

Today, the most important concerns of a country's education system are creating a fertile ground for the growth and development of intellectual capital in knowledge-based information society. The fact that all social groups are able to effectively participate in such a society, need continuous learning, creativity, innovation and active and constructive participation in social learning. Achieving this requires a new definition of the role and function of schools as the main re-education institutions in the society. The educational system needs to school with the use of information and communication technology (ICT), provides the possibility of online learning and new opportunities for people to experience life in the information society, so that this technology not as an instrument, but also in terms of enabling infrastructure for professional education and training. Smart schools are an environment that has the potential necessary to accomplish this goal. The role of smart schools in important variables such as emotional intelligence, achievement motivation and academic performance makes the role of smart schools brighter and stronger. Using and applying smart and updated technology, on the one hand, improve the teachinglearning in teachers and students, the teachers and students to use the World Wide Web can upgrade their academic level and the development of the country. However, the lack of infrastructure such as LAN and Internet connection, consistent lack of structure, lack of familiarity with new teachers, insufficient human resources trained, lack of physical and financial resources to equip schools, intelligent computer systems and equipment and supplies required by the school, including the problems that led to reduce benefits and positive effects of smart schools in Iran.

Qualitative and quantitative investment and development of a smart schools in the country, can have positive and long term outcomes that one of the most important of which are: to promote the science and scientific teaching - learning, research centered and student-centered processes of education ; creating a dynamic and attractive environment to a full bloom of talent and creativity of individual and collective of students, creating an environment suitable for continuous investigation and proportional to the talents and the development of students, growth and development of intellectual, physical, emotional, psychological, cognitive, social and technical and vocational skills of students, increased attendance, participation and interaction between students, teachers, parents and other stakeholders in the teaching - learning process of students, field development, store information and cultural capital of manpower of schools in various aspects of religious, cultural, scientific, educational, research, etc. and plan by achieving the goal of science in the country and the development of perceptual, verbal, social, professional skills of students cited.

\section{References}

Bakhshi Sureshjani, Leila. (2008). Relationship between emotional intelligence and mental health 
and academic performance of male and female students of Islamic Azad University PA. Journal of Research in Educational Sciences-University Curriculum Development Branch (3) 19, 116-97

Barker, S. (2002). A prospective longitudinal investigation of social problem-solving appraisal on adjustment to university, stress, health and academic motivation and performance. Personality \& Individual Differences, 35, 569, 591.

Bar-on, R. (2000). The emotional quotient inventory (EQ-I): A measure of emotional intelligence. Toronto. Canada: multi-health system.

Bar-On, R. (2005). Bar-on model of emotional-social intelligence (ESI). Consortium for Research on Emotional Intelligence in Organizations.Retrieved November 21 , 2009,from http://www.eiconsortium.org/pdf/baron_model_of_emotional_social_intellig nce.pdf.

Bar-On, R. (2006). The Bar-On Model of Emotional-Social Intelligence (ESI). Psicothema, 18, supl., 13-25.

Cross, D. R., \& Paris, S. G. (1988). Developmental and instructional analyses of children's metacognition and reading comprehension. Journal of Educational Psychology, 80(2), 131-142.

Falavell, John. H (1377). Cognitive development, translation Farhad Maher, Roshd press

Fardanesh, Hashem. (2004). Theoretical Foundations of Educational Technology. Tehran: Samt

Fartash K. \& Davoudi, S.M.M. (2012). Organizational learning: A key to achieve organizational success and to prevent organizational downfall. Spectrum: A journal of multidisciplinary research, volume 1 , issue 2 , pp. 19-40.

Glover, J. M., \& Bruning, R.H.(1990). Educational psychology: Principles and Application. Boston: Little, Brown.

Goleman, D. (2007). Emotional intelligence: Why it can matter more than IQ. New York, NY: Random House.

Goleman, Daniel. (2001). Emotional Intelligence. Translation Nasrin Parsa. Tehran, publisher of growth. (Since publication of the original language, 1995)

Good, T., \& Brophy, J. (1995). Contemporary educational psychology (5th ed). New York: Harper Collins.

Hatami, Javad Taghizadeh, J., and Mohebinia, J. (2012). Relationship between emotional intelligence, self-regulated learning and academic self-concept and academic performance in high school third grade male students in Kashan city. Journal of Educational Studies and School, 2 (12), 34-27

http://dl.eram.shirazu.ac.ir/root/Utility/eLearning/shivehnameh_hoshmandsazi-900508.pdf

Jafari, Mehdi, Ahmad Zadeh, F. (2014). Check the components of emotional intelligence and academic achievement of students. Journal of Kermanshah University of Medical Sciences. 21 (125), $92-85$

Matemba, C. K., Awinja, J., Otieno, K. O. (2014). Relationship between Problem Solving Approaches and Academic Performance: A Case of Kakamega Municipality, Kenya. International Journal of Human Resource Studies, 4 (4), 10-20.

Mesrabadi, J. (2001). The effectiveness of learning strategies for high-speed reading, retention and comprehension in different contexts. MA thesis. Allameh Tabatabaei University

Ministry of Education. (2011). A smart way to school. Downloaded from the site:

Mirzajani, H., \& Delaviz Bayekolaei, M. (2013). Emotional Intelligence of Students in Smart School. Middle-East Journal of Scientific Research 18 (9): 1322-1329, 2013. ISSN 1990-9233.

Perera, H, N. (2016): The Role of Trait Emotional Intelligence in Academic Performance: Theoretical Overview and Empirical Update. The Journal of Psychology: Interdisciplinary and Applied, 150 (2), 227-249.

Pressley, M. Brokowshi, j. G. \& Schreider, W. (1987). Cognitive Strategies: good strategy users coordinate metacognation and knowledge. Angals of child Development, V4. 89-129.

Rastgar AA. \& Davoudi, S.M.M. (2012). A study of the relationship between employees' spiritual intelligence and job satisfaction: A survey in Iran's banking industry. Spectrum: A journal of multidisciplinary research, volume 1 , issue 2, pp. 57-74.

Rastgar AA. \& Davoudi, S.M.M. (2012). The link between workplace spirituality, organizational citizenship behavior and job performance in Iran. Arth Prabhand: A journal of economics and management, volume 1 , issue 2, pp. 13-29.

Saif Ali Akbar. (2008). Modern educational psychology. Tehran: Publication time

Seifert \& Wheeler, P.(1995). Enhancing motivation: a classroom application of self-instruction strategy training. Research in Education, 51, 1-10.

Shaveran, HR: Salimi, G., Homaee, Reza. (2008). Measure the academic performance of students based on their multiple cultures. Journal of Isfahan University. (1) 9, 160-147 